\title{
Neonatal T-cell maturation and homing receptor responses to Toll-like receptor ligands differ from those of adult naive T cells: relationship to prematurity
}

\author{
Maricruz Crespo', Denise G. Martinez ${ }^{2}$, Adam Cerissi², Brenda Rivera-Reyes' ${ }^{1}$ Helene B. Bernstein ${ }^{3}$, Michael M. Lederman ${ }^{4}$, \\ Scott F. Sieg ${ }^{4}$ and Angel A. Luciano ${ }^{2}$
}

INTRODUCTION: Inflammation and infection are associated with premature birth and with activation of the fetal immune system. We hypothesized that exposure to microbial Toll-like receptor (TLR) ligands plays an important role in neonatal T-cell maturation and that early exposure to microbial products may result in early T-cell maturation and a tendency for these matured effector cells to change their homing receptor patterns.

RESULTS: Expression of the CD45RO marker was induced in term neonatal T cells after in vitro exposure to TLR ligands for 7 days. Interestingly, naive $T$ cells from adult blood were unaffected by TLR ligand exposure. In addition, neonatal T cells had more cells with decreased expression of the a $4 \beta 7$ integrins and increased expression of CCR4 after in vitro exposure of TLR ligands - similar to the expression of these molecules in adult naive T cells.

DISCUSSION: These findings are relevant for the understanding of neonatal T-cell maturation and may contribute to our understanding of multiorgan inflammatory complications of prematurity.

METHODS: Cord blood was obtained from term and preterm infants. Using flow cytometry, we identified a mature $\left(\mathrm{CD} 45 \mathrm{RO}^{+}\right)$phenotype in preterm infant cord blood (CB) T cells that had decreased expression of the $a 4 \beta 7$ integrins and increased expression of the $\mathrm{C}-\mathrm{C}$ chemokine receptor 4 (CCR4) as compared with term infant CB.

T he limited functional capacity of the neonatal immune system increases the neonatal risk for infections (1), rendering the neonate at risk for certain complications (2-5). Preterm infants are especially susceptible to infections and morbidities that are linked to an unusual state of immune activation $(2,6,7)$.

Although the determinants of immune activation in the premature infant are not well understood, in some cases, it may be related to in utero exposure to inflammation from chorioamnionitis. Microbial products (e.g., endotoxin and bacterial DNA) in the amniotic fluid have been detected in the presence of chorioamnionitis $(8,9)$ and are related to a systemic inflammatory response in the fetus (10). Boggess et al. demonstrated in an animal model that chronic maternal exposure to Porphyromonas gingivalis resulted in maternal systemic dissemination and transplacental passage of bacterial products; fetal exposure was confirmed by detection of 16s DNA by PCR in both maternal and fetal compartments (11).

Antigen exposure is necessary to induce maturation of the adaptive immune system; thus, neonatal lymphocytes are predominantly naive and have a "resting" phenotype, as exposure to foreign antigen in utero is uncommon in uncomplicated pregnancies $(1,12)$. Among preterm infants, however, $\mathrm{T}$ cells are often activated as reflected by increased proportions of cells expressing the activation markers CD25, CD69, and human leukocyte antigen D-related (HLA-DR) as compared with T cells of term infants (13).

In this study, we characterized the maturation phenotype and expression of homing receptors in $\mathrm{T}$ cells from the cord blood (CB) of term and preterm infants. T cells from preterm infants showed evidence of in vivo activation and evidence of maturation towards a memory phenotype. In addition, T cells from term infants (composed largely of naive $\mathrm{T}$ cells) but not naive $\mathrm{T}$ cells obtained from adult subjects can be activated in vitro by exposure to microbial Toll-like receptor (TLR) ligands to develop a more mature phenotype and to alter homing receptor expression. We suspect, therefore, that microbial products can play an important role in phenotypic maturation in the neonate but not in adults.

\section{RESULTS}

The Proportion of $\mathrm{CD} 45 \mathrm{RO}^{+} \mathrm{T}$ Cells Is Higher in Preterm vs. Term CB $\mathrm{T}$ cells were identified by size, granularity, and expression of $\mathrm{CD} 45$ and $\mathrm{CD} 3$ (Figure 1a,b). The proportion of $\mathrm{CD}^{+} \mathrm{CD}^{+} 5 \mathrm{RO}^{+}$ $\mathrm{T}$ cells $($ Figure $2 \mathrm{a})$ was higher in preterm $($ median $=23.1 \%)$ vs. term $\mathrm{CB}$ (median $=2.7 \%$ ) (Figure $2 \mathrm{~b})$. This difference was statistically significant $(P=0.0004)$.

Microbial TLR Ligands Increase the Expression of CD45RO in Neonatal T Cells but Not in Adult Naive T Cells

TLR ligands activate cells of the innate immune system in neonates and adults (14-16). As we previously described, TLR ligands

\footnotetext{
'Department of Pediatrics, Case Western Reserve School of Medicine, Case Western Reserve University, Cleveland, Ohio; ${ }^{2}$ Department of Pediatrics, University of South Florida College of Medicine, University of South Florida, Tampa, Florida; ${ }^{3}$ Department of Reproductive Biology, Case Western Reserve School of Medicine, Case Western Reserve University, Cleveland, Ohio; 'Department of Medicine, Case Western Reserve School of Medicine, Case Western Reserve University, Cleveland, Ohio.

Correspondence: Angel A. Luciano (aluciano@health.usf.edu) 


\section{Crespo et al. $\quad$ Articles}

a

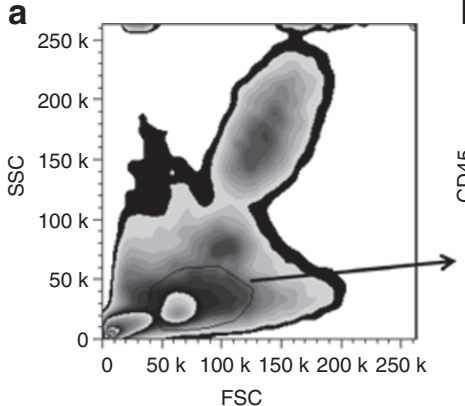

b

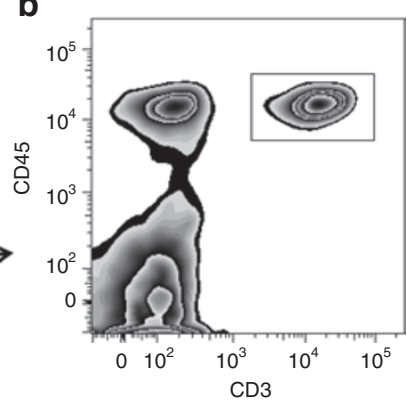

Figure 1. Whole-blood flow cytometric analysis of lymphocytes. CB was stained with fluorochrome-labeled antibodies followed by red blood cell lysis and fixation. (a) Box-plot with lymphocytes gated based on size (forward scatter, FSC) and granularity (side scatter, SSC). (b) Neonatal T cells are selected based on CD45 and CD3 coexpression (box-plot). CB, cord blood.

a
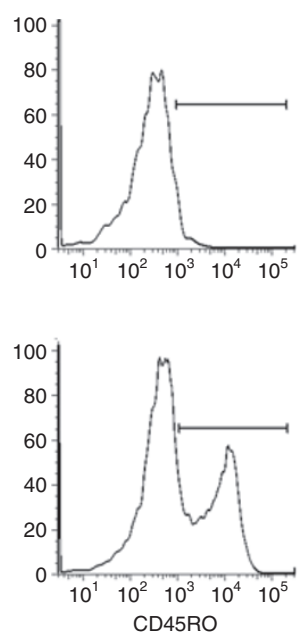

b

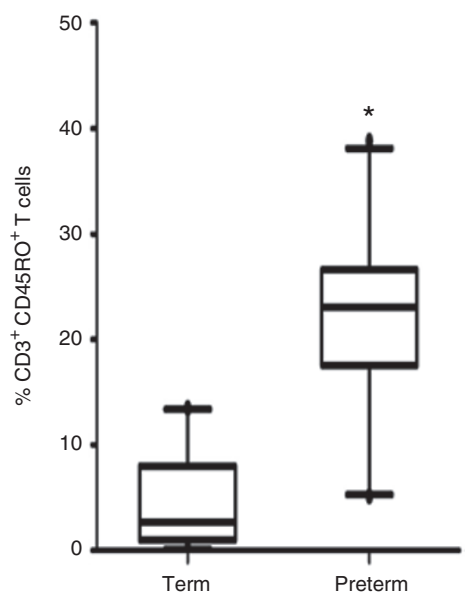

Figure 2. Increased proportion of $\mathrm{CD}^{+} \mathrm{CD} 45 \mathrm{RO}^{+} \mathrm{T}$ cells in $\mathrm{CB}$ of preterm infants. (a) Whole-blood staining from term (upper histogram, 3.5\%) and preterm CB (lower histogram, 35.9\%). $\mathrm{CD}^{2} 5^{+} \mathrm{CD}^{+}$cells were examined for expression of CD45RO. (b) Box and whiskers plot (median, minimum, and maximum values) of proportions of $\mathrm{CD}^{+}{ }^{+} \mathrm{CD} 45^{+}$cells expressing $\mathrm{CD} 45 \mathrm{RO}$ in CB from term $(n=25)$ and preterm infants $(n=22)$. Statistical significance was determined by Mann-Whitney rank test $\left({ }^{*} P=0.0004\right)$. $C B$, cord blood.

also can drive T-cell activation. This effect that we described in adult cells was seen uniquely among memory $\left(\mathrm{CD} 45 \mathrm{RO}^{+}\right)$ $\mathrm{T}$ cells. No effect was observed in naive (CD45RA ${ }^{+}$) T cells (17). As we found an increased proportion of $\mathrm{CD} 45 \mathrm{RO}^{+} \mathrm{T}$ cells in $\mathrm{CB}$ of premature infants who are often exposed to microbial elements in the setting of chorioamnionitis, we hypothesized that bacterial TLR ligands might be activating neonatal CD45RA ${ }^{+}$ $\mathrm{T}$ cells to upregulate expression of CD45RO. TLR ligands were selected based on their expression by bacteria that commonly cause intrauterine infection and neonatal sepsis $(18,19)$. Among $\mathrm{CD}_{4} 5^{+} \mathrm{CD}^{+}$lymphocytes, there was a significant increase in the proportion of $\mathrm{CD}^{+}$cells expressing CD45RO (Figure 3a). Incubation with flagellin resulted in the highest median percentage of CD45RO (14\%), followed by macrophage-activating lipopeptide-2 (11\%) and lipopolysaccharide (9\%) (Figure 3b). By contrast, these TLR ligands did not induce CD45RO expression
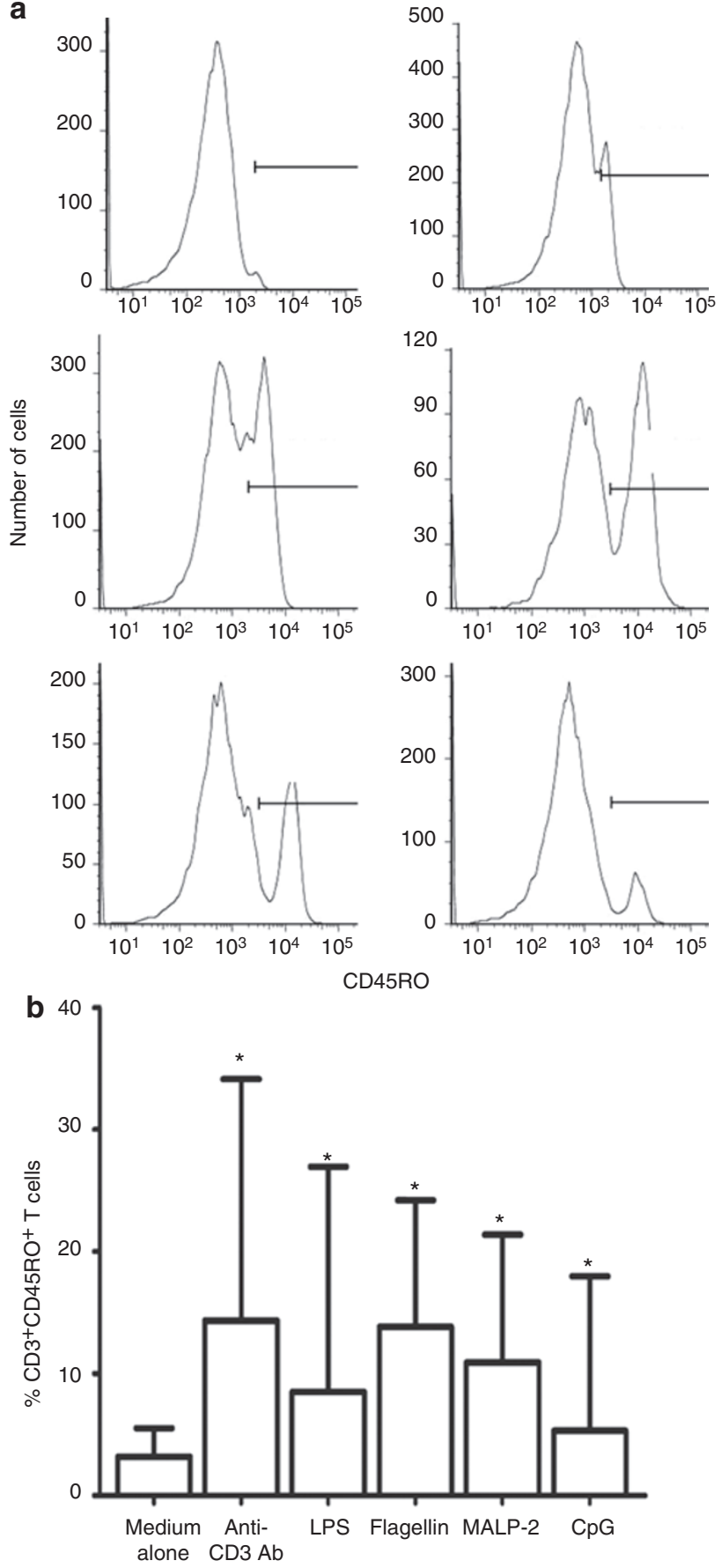

Figure 3. TLR ligands increased the proportion of neonatal T cells expressing CD45RO. (a) CBMCs from term infants were cultured for 7 days in the presence of anti-CD3 antibody or TLR ligands (LPS, flagellin, MALP2 , and $\mathrm{CpG}$ ). Cells were then analyzed by flow cytometry, gated for the expression of CD45 and CD3, and further evaluated for the expression of CD45RO (histograms). (a) Representative histograms of expression of CD45RO in T cells in the presence of medium alone (1.2\%) and anti-CD3 antibody (15.6\%) (first row), LPS (35.2\%) and flagellin (39.1\%) (second row), and MALP-2 (27.8\%) and CpG (8.9\%) (third row). (b) Summary data representing median and interquartile ranges of $C D 3^{+} \mathrm{CD} 45 \mathrm{RO}^{+}$cells in CB of term infants $(n=18)$ after in vitro incubation in medium or medium supplemented with anti-CD3 or selected TLR ligands. Statistical significance for difference between medium alone and TLR groups ( $\left.{ }^{*} P<0.05\right)$ was determined by Mann-Whitney rank test. $C B$, cord blood; $C B M C$, cord blood mononuclear cell; $\mathrm{CpG},-\mathrm{C}$-phosphate-G- site; LPS, lipopolysaccharide; MALP-2, macrophage-activating lipopeptide-2; TLR, Toll-like receptor. 

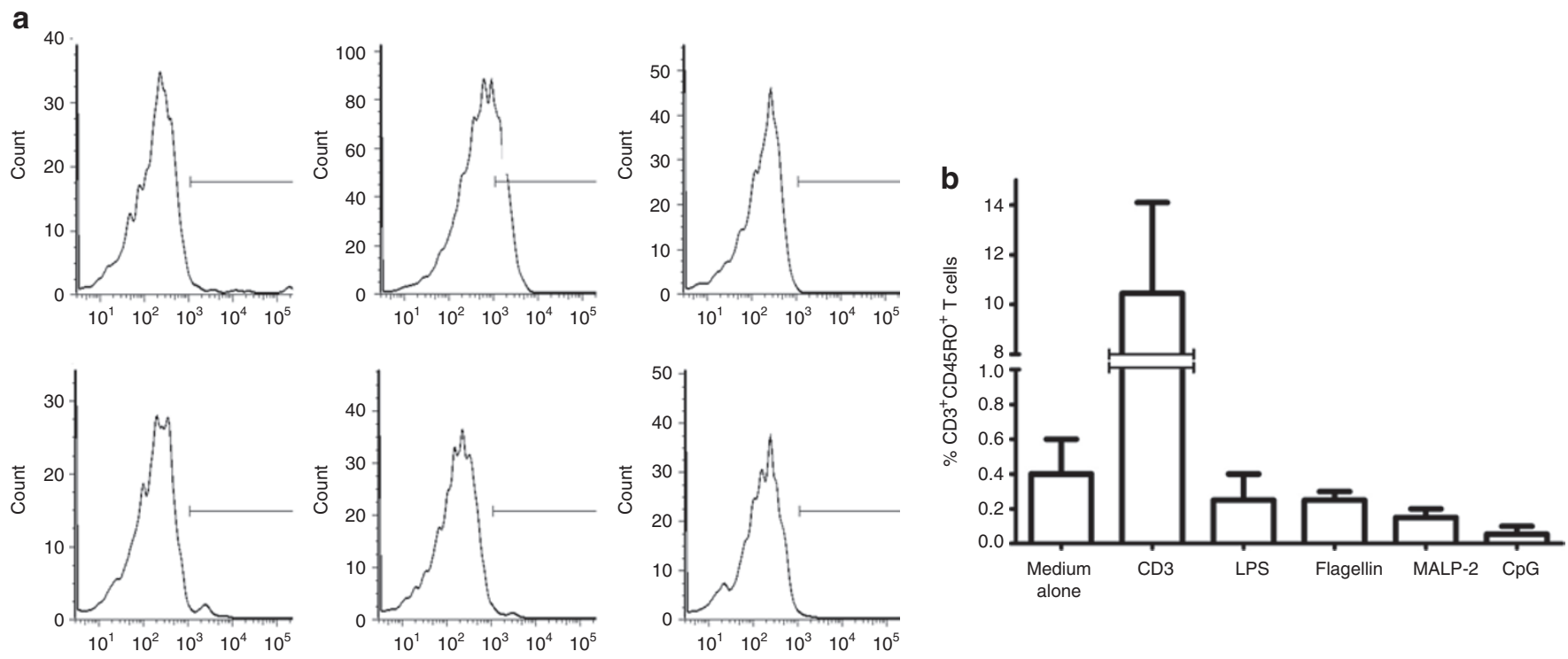

$C D 45 R O$

Figure 4. TLR ligand exposure does not increase the expression of CD45RO in naive T-cell-enriched adult PBMCs. (a) CD45RO-depleted PBMCs from healthy adults were cultured for 7 days in the presence of anti-CD3 or selected TLR ligands and then examined for expression of CD45RO (histograms). First row: medium alone (0.6\%), anti-CD3 (14.1\%), and LPS (0.1\%). Second row: flagellin (0.7\%), MALP-2 (0.5\%), and CpG (0.2\%). (b) Summary data representing three experiments. CpG, -C-phosphate-G- site; LPS, lipopolysaccharide; MALP-2, macrophage-activating lipopeptide-2; PBMC, peripheral blood mononuclear cell; TLR, Toll-like receptor.

when incubated with naive $\mathrm{T}$ cells (CD45RO-depleted) from healthy adults (Figure 4a,b).

Distinct Homing Receptor Patterns Manifested by Preterm, Term, and Adult Naive (CD45RA ${ }^{+}$) T Cells

The traffic of $\mathrm{T}$ lymphocytes from blood to tissues occurs via a series of interactions between lymphocytes and endothelial cells (20). Naive T cells typically traffic through secondary lymphoid organs in search of peptides bound to major histocompatibility complex molecules expressed by antigen-presenting cells. Upon encounter with antigen and T-cell-receptor triggering, these naive $\mathrm{T}$ cells gain distinct homing characteristics (21). Following priming, clonal expansion, and differentiation, these matured $\mathrm{T}$ cells leaving the lymph node acquire new migration capabilities (22). T cells activated and matured in Peyer's patches or mesenteric lymph nodes typically express C-C chemokine receptor 9 (CCR9) and the integrin $\alpha_{4} \beta_{7}$, whereas activation in peripheral lymph nodes draining nongastrointestinal tissues, such as the skin and the lung, typically results in upregulation of CCR4 (23).

Cells were assessed for surface expression of $\mathrm{CD} 3$ and homing receptors $\alpha_{4} \beta_{7}$ and CCR4 (Figure 5a). Among adult T cells $\left(\mathrm{CD} 45^{+} \mathrm{CD}^{+}\right), 55 \%$ were $\alpha_{4}{ }^{+} \beta_{7}{ }^{+}, 27 \%$ were $\alpha_{4}{ }^{+} \beta_{7}{ }^{-}, 12 \%$ were $\alpha_{4}{ }^{-} \beta_{7}{ }^{-}$, and only $4 \%$ were $\alpha_{4}{ }^{-} \beta_{7}{ }^{+}$. In contrast, $92 \%$ of T cells from term infants were $\alpha_{4}^{+} \beta_{7}{ }^{+}, 5 \%$ were $\alpha_{4}^{+} \beta_{7}^{-}, 3 \%$ were $\alpha_{4}{ }^{-} \beta_{7}^{-}$, and $0 \%$ were $\alpha_{4}^{-} \beta_{7}{ }^{+}$. Of note, the homing receptor pattern differed between preterm and term infant T cells (Figure 5b). Preterm infant T cells had a lower proportion of cells that were $\alpha_{4}{ }^{+} \beta_{7}{ }^{+}$ (median values of $80 \%$ and $92 \%$ for preterm and term, respectively; $P=0.0034$ ) and a higher proportion of cells that did not express the $\beta_{7}$ homing receptor (median values of $16 \%$ and $8 \%$ in preterm and term infants, respectively; $P=0.0034$ ). There was no difference in the expression of CCR4 on T cells between term and preterm infant cells.

In Vitro Exposure of Neonatal T Cells to Microbial TLR Ligands Alters the Expression of Homing Receptors

After incubation with selected TLR ligands, the percentage of $\mathrm{CD}^{+}{ }^{+}{ }_{4}^{+} \beta_{7}{ }^{+}$cells in term infant T cells decreased as compared with cells incubated with medium (Figure 6a,b); this decrease was primarily due to decreased expression of the $\beta_{7}$ integrin (lipopolysaccharide $93 \% \alpha_{4}^{+} \beta_{7}^{-}$, flagellin $62 \% \quad \alpha_{4}{ }^{+} \beta_{7}{ }^{-}$, macrophage-activating lipopeptide-2 $80 \% \quad \alpha_{4}{ }^{+} \beta_{7}$, -C-phosphate-G- site (CpG) $\left.42 \% \alpha_{4}^{+} \beta_{7}^{-}\right)$. We analyzed the expression of CCR4 in the $\mathrm{CD}^{+} \alpha_{4}^{+}$subpopulation that did or did not express $\beta_{7}$ (Figure 7a,b) and found that decreased expression of the $\beta_{7}$ integrin was accompanied by increased expression of CCR4 after exposure to TLR ligands. This effect was especially striking in lipopolysaccharide-exposed cells (Figure 7b).

Chorioamnionitis Affects the Expression of CD45RO and the $\alpha_{4} \beta_{7}$ Receptors in Neonatal T Cells

The proportion of $\mathrm{T}$ cells expressing CD45RO was compared between infants exposed to clinical chorioamnionitis $(n=5)$ and those without clinical chorioamnionitis $(n=41)$ (Figure 8a). The proportion of $\mathrm{CD}^{+} \mathrm{CD}_{4} 5 \mathrm{RO}^{+}$was higher in the group with clinical chorioamnionitis $($ median $=25 \%)$ vs. no clinical chorioamnionitis (median $=6.9 \%)$. This difference was statistically significant $(P=0.008)$. There was no significant difference $(P=0.37)$ in the proportion of $\mathrm{CD}^{+} \mathrm{CD} 45 \mathrm{RO}^{+} \mathrm{T}$ cells of preterm infants born to mothers without clinical chorioamnionitis $($ median $=23.1 \%)$, 
a
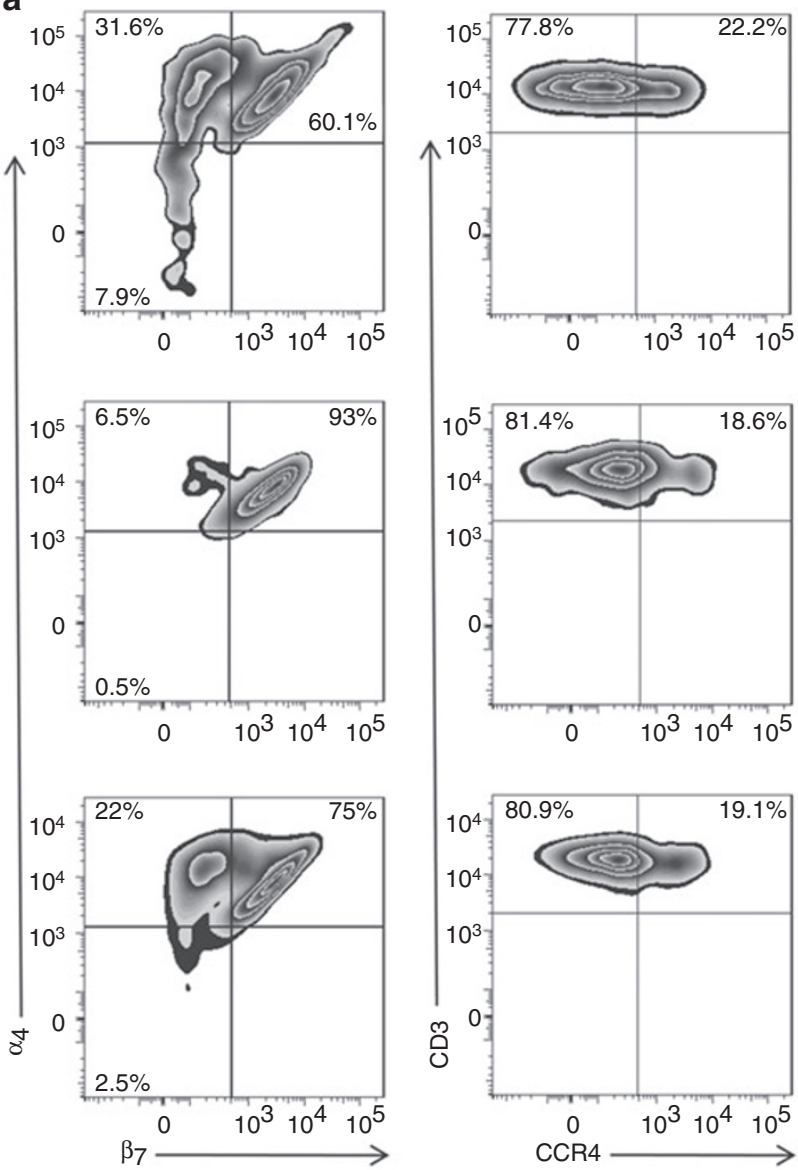

b

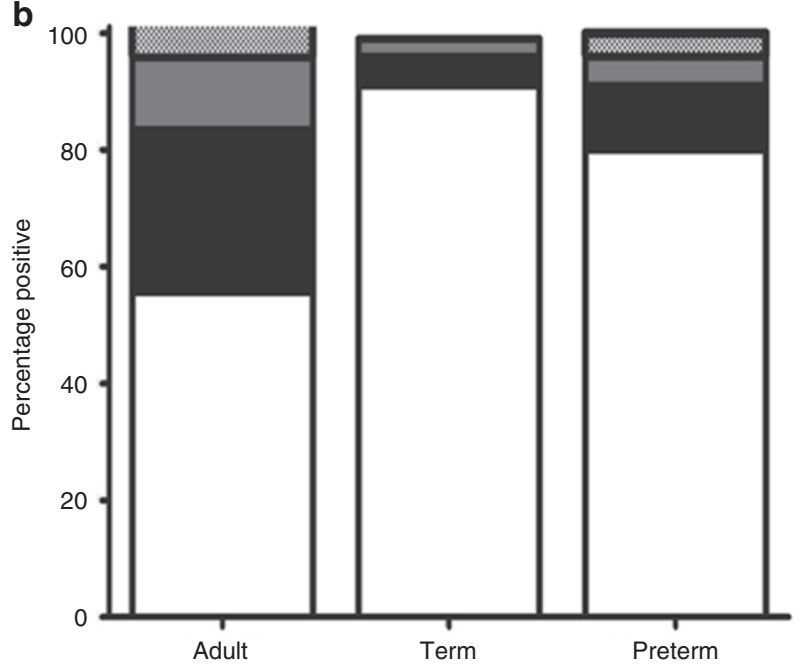

Figure 5. Differential homing receptor distribution in adult, term, and preterm T cells. (a) Adult peripheral blood (first row), term infant $\mathrm{CB}$ (second row), and preterm infant $\mathrm{CB}$ (third row). $\mathrm{CD} 45^{+} \mathrm{CD} 3^{+}$cells were examined for expression of the homing receptors $\alpha_{4} \beta_{7}$ and CCR4 (box-plots). (b) Stacked bars graph comparing the distribution of the $\alpha_{4} \beta_{7}$ receptor among $\mathrm{CD}^{+} \mathrm{T}$ cells in adults $(n=10)$ and term $(n=22)$, and preterm infants $(n=26)$. White bars represent $a_{4}{ }^{+} \beta_{7}{ }^{+} T$ cells, black bars $a_{4}{ }^{+} \beta_{7}^{-} T$ cells, gray bars $\mathrm{a}_{4}{ }^{-} \beta_{7}-\mathrm{T}$ cells, and dotted bars $\mathrm{a}_{4}^{-} \beta_{7}{ }^{+}$T cells. Statistical significance $(P<0.0001)$ was determined by ANOVA. CB, cord blood; CCR, $\mathrm{C}-\mathrm{C}$ chemokine receptor. those born to mothers with clinical chorioamnionitis (median $=28.1 \%$ ), and those born to mothers with histological chorioamnionitis (median $=23.2 \%$ ) (Figure $8 b)$. The proportion of $\mathrm{CD}^{+} \alpha_{4}{ }^{+} \beta_{7}{ }^{-}$was also significantly increased in infants exposed to clinical chorioamnionitis (median $=14.3 \%$ ) and histological chorioamnionitis (median $=12.6 \%$ ) as compared with those without exposure $($ median $=6.5 \%)(P \leq 0.0001)$ (Figure 9$)$.

\section{DISCUSSION}

Although the neonatal immune system lacks memory of prior antigen exposure, it provides defense, albeit limited, against microbial pathogens while it is maturing and developing responses to newly encountered antigens. In this study, we report a novel characteristic of neonatal $\mathrm{T}$ cells that distinguishes them from adult $\mathrm{T}$ cells. We previously demonstrated that preterm labor is associated with neonatal T-cell activation, as evidenced by an increased proportion of cells expressing the activation markers CD25, CD69, and HLA-DR (13). In this study, we also report an increased proportion of $\mathrm{T}$ lymphocytes expressing the maturation antigen $\mathrm{CD} 45 \mathrm{RO}$ in preterm $\mathrm{CB}$ and a distinct homing receptor pattern that distinguishes preterm infant $\mathrm{T}$ cells from term infant $\mathrm{CB}$ and adult $\mathrm{T}$ cells. Finally and most strikingly, we report that, in response to TLR ligand exposure, neonatal $\mathrm{T}$ cells have the capacity to acquire a maturation phenotype and that adult naive T cells lack this capacity. These observations provide novel insights into immune responsiveness of the neonate and the potential role of innate responses in the maturation of the adaptive immune system.

In adults, the principal stimulus for naive T-cell activation and maturation is considered to be T-cell-receptor triggering by neoantigenic peptides. In this study, however, we demonstrate that neonatal naive $\mathrm{T}$ cells can upregulate expression of the maturation antigen CD45RO through TLR-dependent mechanisms. Using selected TLR ligands, we found consistent upregulation of CD45RO by neonatal T cells. Of note, this response is lost in adult naive T cells. In the murine model, neonatal and adult naive $\mathrm{T}$ cells exhibit phenotypical and functional differences whereby neonatal naive $\mathrm{T}$ cells exhibit a higher level of effector Th1/Th2 cytokine production and an early proliferation response to stimulation with IL-7 (24). Our study indicates there is an additional difference between neonatal and adult cells. We speculate that the apparent maturation phenotype of neonatal $\mathrm{T}$ cells that we found in preterm $\mathrm{CB}$ may be driven by in vivo exposure to bacterial products. In utero exposure to plasmodial products that cross the placenta have been linked to altered neonatal immune responses to immunizations $(25,26)$. We found a significant difference in the pattern of maturation and homing receptors in infants exposed to chorioamnionitis. This in utero maturation process could be related to placental inflammation. Of note, the analysis restricted to only preterm infants showed no differences between infants exposed to chorioamnionitis (either clinical or histological) and those not exposed to chorioamnionitis. These results should be interpreted very carefully because of the relatively small preterm group. Other factors should be taken into consideration that may increase the passage of bacterial products to the fetus, 

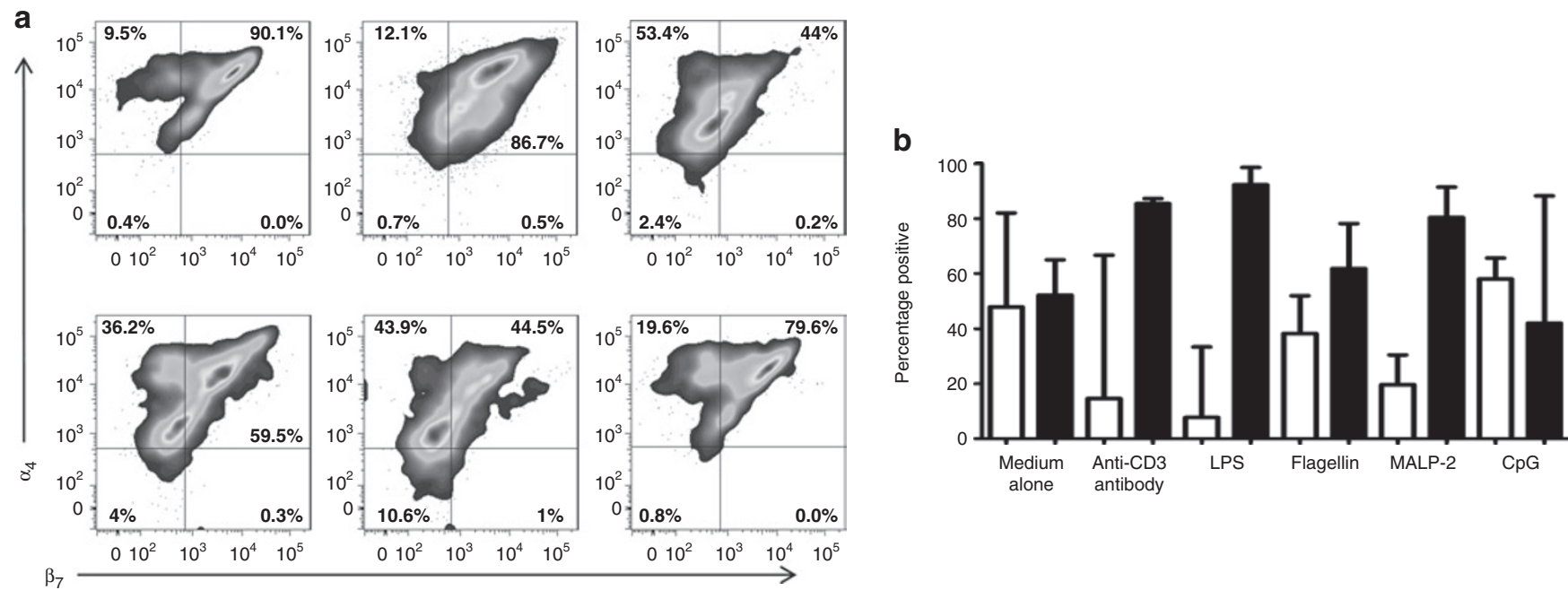

Figure 6. TLR ligands change the proportion of neonatal T cells expressing the $a_{4} \beta_{7}$ homing receptor. (a) CBMCs from term infants were cultured for 7 days in the presence of medium alone, anti-CD3 antibody, and LPS (first row), and flagellin, MALP-2, and CpG (second row). Cells were analyzed by flow cytometry, gated for the expression of $C D 45$ and $C D 3$, and further evaluated for the expression of the $\alpha_{4} \beta_{7}$ receptor (box-plots). (b) Column bar graph comparing cumulative data of the distribution of the $a_{4} \beta_{7}$ receptor in $C D 3^{+} C D 45 R O^{+}$cells in $C B$ of term infants $(n=16)$ after exposure to TLR ligands. White bars represent percentage of cells positive for $\mathrm{a}_{4}^{+} \beta_{7}{ }^{+}$and black bars represent percentage of cells positive for $\mathrm{a}_{4}{ }^{+} \beta_{7}{ }^{-}$. Statistical significance $(P<0.0001)$ was determined by ANOVA. Median values are shown. CB, cord blood; CBMCs, cord blood mononuclear cells; CpG, -C-phosphate-G- site; LPS, lipopolysaccharide; MALP-2, macrophageactivating lipopeptide-2; TLR, Toll-like receptor.
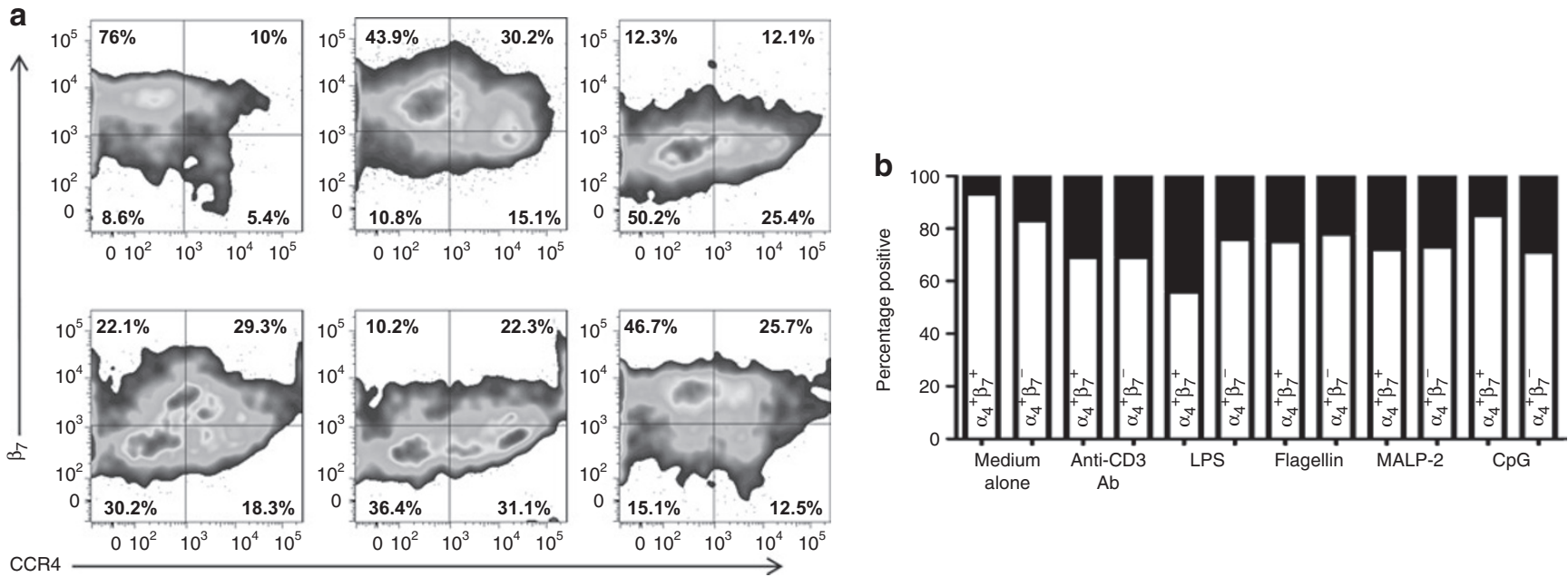

Figure 7. Increased proportion of neonatal $\mathrm{CD}^{+} \mathrm{T}$ cells expressing CCR4 after exposure to TLR ligands. (a) CBMCs from term infants were cultured for 7 days in the presence of medium alone, anti-CD3 antibody, and LPS (first row), and flagellin, MALP-2, and CpG (second row). Cells were analyzed by flow cytometry; gated for the expression of CD45, CD3, $a_{4^{\prime}}$ and further evaluated for the expression of $\beta_{7}$ and CCR4 (box-plots). (b) Stacked bars graph comparing the distribution of the $\beta_{7}$ subunit and CCR4 receptor among CD3 ${ }^{+} a_{4}^{+}$T cells in term infants $(n=16)$. White bars represent CCR4-negative cells and black bars represent CCR4-positive cells. Statistical significance $(P<0.0001)$ was determined by ANOVA. CBMC, cord blood mononuclear cell; CCR, C-C chemokine receptor; CpG, -C-phosphate-G- site; LPS, lipopolysaccharide; MALP-2, macrophage-activating lipopeptide-2.

such as the duration of the rupture of membranes, presence of bacteria in maternal urine and/or blood, maternal periodontal disease, and presence of bacteria that are difficult to grow in cultures and whose presence could be detected only by PCR. Future studies should include measurement of microbial products in CB samples. We are currently investigating whether the maturation effect is mediated directly through TLR receptors in $\mathrm{T}$ cells or if antigen-presenting cells are needed.

To our knowledge, this is the first demonstration of a distinct homing receptor pattern in preterm infant $\mathrm{CB} \mathrm{T}$ cells that differs from those of term infant and adult $\mathrm{T}$ cells. Lymphocyte migration is highly regulated, which ensures that distinct cell populations are delivered to intended site(s) in the proper physiological or pathological context (27). Homing receptors that are important for T-cell homeostasis include $\alpha_{4} \beta_{7}$ and CCR4. The homing molecule $\alpha_{4} \beta_{7}$ promotes T-cell entry into intestinal sites and CCR4 supports T-cell chemotaxis and entry into nongastrointestinal sites through interaction with its ligand induced in the setting of inflammation (28). The high proportion of $\alpha_{4} \beta_{7}$ cells in $\mathrm{CB}$ may reflect the critical role of intestinal homing-and 

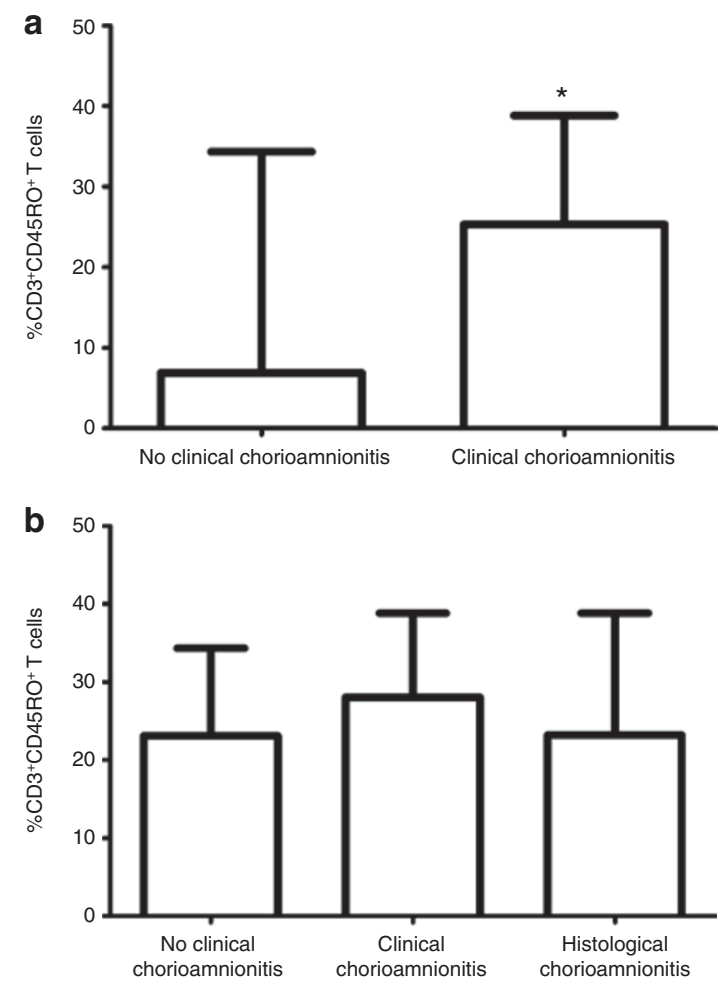

Figure 8. Increased proportion of $\mathrm{CD}^{+} \mathrm{CD} 45 \mathrm{RO}^{+} \mathrm{T}$ cells in infants exposed to chorioamnionitis. (a) Column bar graph comparing proportion of $\mathrm{CD}^{+}{ }^{+} \mathrm{CD} 45 \mathrm{RO}^{+} \mathrm{T}$ cells in infants exposed to clinical chorioamnionitis $(n=5)$ with those not exposed $(n=41)$. This figure includes both term and preterm infants. (b) Column bar graph comparing proportion of $C D 3^{+} C D 45 \mathrm{RO}^{+} \mathrm{T}$ cells in preterm infants exposed to clinical chorioamnionitis $(n=6)$ or histological chorioamnionitis $(n=12)$ with those not exposed $(n=11)$. Statistical significance was determined by Mann-Whitney rank test $\left({ }^{*} P=0.003\right)$.

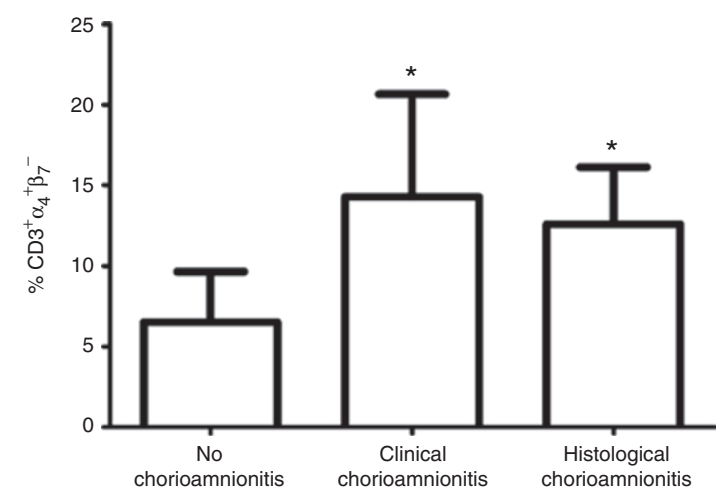

Figure 9. Increased proportion of $\mathrm{CD}^{+} \mathrm{a}_{4}^{+}{ }^{+}{ }_{7}^{-} \mathrm{T}$ cells in infants exposed to chorioamnionitis. Column bar graph comparing proportion of $\mathrm{CD}^{+} a_{4}{ }^{+} \beta_{7}^{-}$ T cells in infants exposed to clinical chorioamnionitis $(n=5)$ or histological chorioamnionitis $(n=12)$ with those not exposed $(n=30)$. This figure includes both term and preterm infants. Statistical significance $\left({ }^{*} P<0.0001\right)$ was determined by ANOVA.

perhaps the importance of exposure to microbial elements in the gut-in neonatal T-cell development (29). In this study, we showed that in vitro exposure of CB cells to microbial TLR ligands alters the expression of these homing receptors, decreasing expression of $\alpha_{4} \beta_{7}$ and increasing the expression CCR4. Our finding of fewer $\alpha_{4}^{+} \beta_{7}^{+}$T cells in preterm CB may reflect an
Table 1. Subject characteristics

\begin{tabular}{lccc}
\hline & $\begin{array}{c}\text { Term } \\
(n=26)\end{array}$ & $\begin{array}{c}\text { Preterm } \\
(n=22)\end{array}$ & Pvalue \\
\hline $\begin{array}{l}\text { Mean gestational age in } \\
\text { weeks (SD) }\end{array}$ & $38.7( \pm 1.1)$ & $30.1( \pm 3.5)$ & $<0.0001$ \\
Race (\%) & 56 & 36 & NS \\
AA & 28 & 50 & \\
C & 16 & 14 & NS \\
H & & & \\
Delivery mode (\%) & 40 & 32 & \\
V & 60 & 68 & \\
C/S & None & 100 & \\
Prenatal antibiotics (\%) & None & 59 & \\
Prenatal steroids (\%) & None & 32 & \\
Prenatal magnesium sulfate & & & \\
exposure (\%) & None & 27 \\
Clinical chorioamnionitis ${ }^{\mathrm{a}}$ (\%) & N/A & 69 \\
Histological chorioamnionitis ${ }^{\mathrm{b}}$ (\%) & & 27 \\
Stage 1 (\%) & & 36 \\
Stage 2 (\%) & & 36 \\
Stage 3 (\%) & & \\
\hline AA Afican & &
\end{tabular}

AA, African American; bpm, beats per minute; C, Caucasian; C/S, Cesarean section; H, Hispanic; N/A, not applicable; V, vaginal.

${ }^{a}$ Defined by fever (an intrapartum temperature $>100.4^{\circ} \mathrm{F}$ or $>37.8^{\circ} \mathrm{C}$ ), significant maternal tachycardia ( $>12 \mathrm{bpm})$, fetal tachycardia (>160-180 bpm), purulent or foul-smelling amniotic fluid or vaginal discharge, uterine tenderness, and maternal leukocytosis (total blood leukocyte count $>15,000-18,000$ cells/ $\mu$ ). ${ }^{\circ}$ Stage 1: neutrophils in placental chorionic plate only; stage 2: neutrophils throughout chorionic plate and subamniotic connective tissue; stage 3: necrotizing inflammation or multifocal abscesses.

earlier (premature) maturation of these cells in response to premature exposure to microbial elements. A consequence of this exposure may be increased migration of these cells to nongastrointestinal sites (e.g., lungs, skin, or brain) that may underlie the systemic inflammatory organ dysfunction often seen in premature infants. Studies are under way to better characterize the effector function and cytokine potential of these cells.

What are the possible clinical implications of T-cell activation/maturation and alteration in homing receptor patterns in the preterm infant? Premature infant morbidities (e.g., bronchopulmonary dysplasia, necrotizing enterocolitis, respiratory distress syndrome, periventricular leukomalacia, and intraventricular hemorrhage) appear to be related to a state of immune activation and inflammation (6,7,30-32). Evidence for this relationship includes direct associations between placental pathology and these morbidities in preterm infants (33) and an increased proportion of $\mathrm{T}$ lymphocytes migrating to lungs and brain in addition to the presence of $\mathrm{CD} 45 \mathrm{RO}^{+} \mathrm{T}$ cells $(6,7,32)$. Here, we demonstrate alterations in T-cell maturation and homing receptor expression in premature infants that may contribute to these morbid events.

Most striking in this study was our finding of a novel and qualitative difference in the way neonatal and adult naive $T$ cells respond to TLR ligand exposure. The apparent maturation 
Table 2. Cell-surface markers, fluorochrome labeling, and function

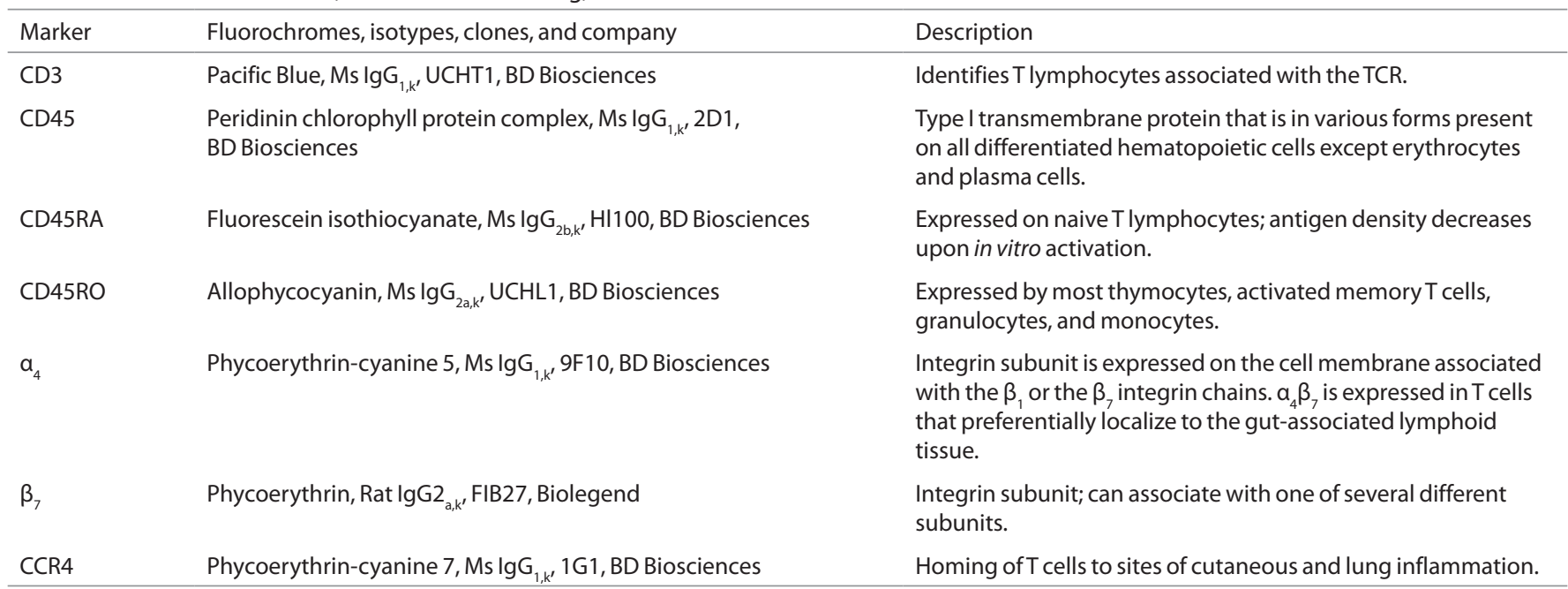

response of neonatal $\mathrm{T}$ cells to these microbial products suggests either that microbial elements are necessary for physiologic maturation of the adaptive immune defenses (34) or that neonates can respond to microbial challenges using mechanisms that are not used by adults with more mature adaptive immune systems. These differences between neonatal and adult cells may relate to several factors including the developmental age of the cells, a history of previous exposure to antigen, differences in the nature of TLR interactions with their ligands, or function of antigen-presenting cells. These possibilities will be important to explore in further investigations.

\section{METHODS \\ Subjects}

$\mathrm{CB}$ samples were obtained from subjects delivered at Case Medical Center/MacDonald's Women's Hospital and Tampa General Hospital after obtaining informed consent from parent(s). Healthy adult donor samples were obtained from the Center for AIDS Research at Case Western Reserve University after obtaining informed consent. These studies were performed in accordance with the policies of and approved by the institutional review boards at Case Western Reserve University/ University Hospitals of Cleveland and the University of South Florida/ Tampa General Hospital. CB samples were obtained from healthy term infants (gestational age $\geq 37$ weeks, $n=26$ ) and preterm infants (gestational age $\leq 36$ weeks, $n=22$ ); and peripheral blood was obtained from healthy adults $(n=10)$. Demographic and clinical details for the infants were obtained from the medical record (Table 1).

\section{Cell Preparation and Flow Cytometry}

$\mathrm{CB}$ from term and preterm pregnancies was collected according to the National Cord Blood Program protocol (35). Peripheral blood was collected from adults by venipuncture and transferred into heparincoated tubes. Cell-surface-molecule expression was assessed in whole blood within $6 \mathrm{~h}$. This rapid analysis permits accurate assessment of the in vivo phenotype state.

Whole blood $(200 \mu \mathrm{l})$ samples were stained for $15 \mathrm{~min}$ in the dark at room temperature with fluorochrome-labeled antibodies (Table 2) and then incubated for 15 min with FACS Lysing Solution (BD Bioscience, San Diego, CA). Cells were washed in wash buffer (phosphate-buffered saline with $1 \%$ bovine serum albumin and $0.1 \%$ sodium azide). Cells were then placed in wash buffer and fixed in 1\% formaldehyde. Cells were analyzed using an LSRII Flow Cytometer (Becton Dickinson, San Jose, CA); FACSDIVA software (version
6.1.1 Bioscience, San Diego, CA) was used to organize the data, and FlowJo software (version 7, Tree Star, Ashland, OR) and Prism 5.0 Graphpad software (La Jolla, CA) were used to analyze the data. Nucleated red blood cells were excluded from the analysis by gating on cells expressing CD45 (36) (Figure 1a). T cells were identified by size, granularity, and expression of CD3 and CD45 (Figure 1b). An average of $6,000 \mathrm{CD}^{+}$events were collected for analysis.

\section{T-Cell Exposure to TLR Ligands}

CB mononuclear cells from term infants were isolated over a FicollHypaque cushion. Density sedimentation was performed twice to improvethepurityofthemononuclearcells(Supplementary FigureS1 online) (37). Cell viability was examined using trypan blue. Cell viability after Ficoll-Hypaque was always higher than 95\%. Cells were cultured in RPMI 1640 (Cambrex BioWhitaker; Walkersville, MD) supplemented with $10 \%$ fetal bovine serum (Hyclone; Logan, Utah), 1\% 2 mmol/l L-glutamine (Cambrex BioWhitaker), and $1 \%$ streptomycin (Cambrex BioWhitaker). Cells were cultured for 7 days with anti-CD3 monoclonal antibody alone (BD Pharmigen, San Diego, CA; $100 \mathrm{ng} / \mathrm{ml}$ ) or individual TLR, as indicated. Lipopolysaccharide (E. coli, lipopolysaccharide $5 \mu \mathrm{g} / \mathrm{ml}$, TLR 4 ligand), flagellin (S. tyhimurium, $100 \mathrm{ng} / \mathrm{ml}$, TLR 5 ligand), macrophage-activating lipopeptide-2 (MALP-2 isolated from Mycoplasma fermentans, $100 \mathrm{ng} / \mathrm{ml}$, TLR 2-6 dimer), and CpG oligodeoxynucleotide 2006 ( $5 \mu \mathrm{g} / \mathrm{ml}$, TLR 9 ligand) were purchased from Imgenex (San Diego, CA). After 7 days, cells were stained with fluorochrome-labeled antibodies to characterize T-cell populations (naive CD45RA ${ }^{+}$, memory CD45RO ${ }^{+}, \alpha_{4} \beta_{7}^{+} \mathrm{T}$ cells, and CCR $4^{+} \mathrm{T}$ cells) (Table 2) and analyzed by flow cytometry, as described above. In addition, cells were stained with propidium iodide for viability at day 4 and day 6 (Supplementary Figure S2 online). Viability remained higher than $92 \%$. Adult peripheral blood mononuclear cells were depleted of $\mathrm{CD}_{4} 5 \mathrm{RO}^{+}$cells by magnetic bead separation and examined for the presence of antigen-presenting cells (Supplementary Figure S3 online). Peripheral blood mononuclear cells were suspended in $80 \mu \mathrm{l}$ of magnetic-activated cell sorting depletion buffer (phosphate-buffered saline, $0.5 \%$ bovine serum albumin, and $2 \mathrm{mmol} / \mathrm{l}$ EDTA) per $10^{7}$ total cells. Then $20 \mu \mathrm{l}$ of CD45RO microbeads (Miltenyi Biotec no. 130-046-001; Miltenyi Biotec, Auburn, CA) were added per $10^{7}$ total cells. Cells were mixed and refrigerated for $15 \mathrm{~min}\left(4-8^{\circ} \mathrm{C}\right)$. Cells were washed by adding $1-2 \mathrm{ml}$ of depletion buffer per $10^{7}$ cells and centrifuged for $10 \mathrm{~min}$. Cells were then resuspended in $500 \mu \mathrm{l}$ of buffer and run in the AutoMACS Magnetic Separator (Miltenyi Biotec) using the "Depletes" separation program. Depletion of CD45RO ${ }^{+}$cells was confirmed by flow cytometry and the resulting T-cell populations 
were determined to be $>95 \%$ CD $45 \mathrm{RA}^{+} \mathrm{CD} 45 \mathrm{RO}^{-}$. Neonatal T-cell populations were examined for the presence of $\mathrm{CD}^{2} 5 \mathrm{RO}^{+} \mathrm{T}$ cells before culture. CD45RO ${ }^{+} \mathrm{T}$ cells in $\mathrm{CB}$ samples were $<5 \%$.

\section{Placental Pathology}

A histological placental diagnosis was also used because chorioamnionitis could still be present even in the absence of clinical symptoms. This diagnosis is routinely performed in placentas of preterm infants born at Tampa General Hospital and MacDonald's Women's Hospital. Results are summarized in Table 1.

\section{Statistical Methods}

Group medians were compared for statistically significant differences using a Mann-Whitney rank test or ANOVA; a $P$ value of 0.05 was considered statistically significant. We analyzed the samples and generated graphs using GraphPad Prism 5 (La Jolla, CA).

SUPPLEMENTARY MATERIAL is linked to the online version of the paper at http://www.nature.com/pr

\section{ACKNOWLEDGMENTS}

The authors thank the Cleveland Immunopathogenesis Consortium, the research nurses, and the fellows at Rainbow Babies and Children's Hospital and Tampa General Hospital.

\section{STATEMENT OF FINANCIAL SUPPORT}

This work has been supported by grants from the Rainbow Babies and Children's Foundation Fellowship Research Award, the NICHD Research Career Development in Child Health (K12 HD057581), the Case Western Reserve University Center for AIDS Research (Al-36219), the National Institutes of Health (Al 076174), and the Tampa General Hospital Office of Clinical Research Award.

\section{REFERENCES}

1. Trivedi HN, HayGlass KT, Gangur V, Allardice JG, Embree JE, Plummer FA. Analysis of neonatal T cell and antigen presenting cell functions. Hum Immunol 1997;57:69-79.

2. Stoll BJ, Hansen N. Infections in VLBW infants: studies from the NICHD Neonatal Research Network. Semin Perinatol 2003;27:293-301.

3. Gonçalves LF, Chaiworapongsa T, Romero R. Intrauterine infection and prematurity. Ment Retard Dev Disabil Res Rev 2002;8:3-13.

4. Hamada S, Vearncombe M, McGeer A, Shah PS. Neonatal group B streptococcal disease: incidence, presentation, and mortality. J Matern Fetal Neonatal Med 2008;21:53-7.

5. Yurdakök M. Antibiotic use in neonatal sepsis. Turk J Pediatr 1998; 40:17-33.

6. Duggan PJ, Maalouf EF, Watts TL, et al. Intrauterine T-cell activation and increased proinflammatory cytokine concentrations in preterm infants with cerebral lesions. Lancet 2001;358:1699-700.

7. Turunen R, Vaarala O, Nupponen I, et al. Activation of T cells in preterm infants with respiratory distress syndrome. Neonatology 2009;96:248-58.

8. Jalava J, Mäntymaa ML, Ekblad U,et al. Bacterial $16 \mathrm{~S}$ rDNA polymerase chain reaction in the detection of intra-amniotic infection. Br J Obstet Gynaecol 1996;103:664-9.

9. Romero R, Roslansky P, Oyarzun E, et al. Labor and infection. II. Bacterial endotoxin in amniotic fluid and its relationship to the onset of preterm labor. Am J Obstet Gynecol 1988;158:1044-9.

10. Gotsch F, Romero R, Kusanovic JP, et al. The fetal inflammatory response syndrome. Clin Obstet Gynecol 2007;50:652-83.

11. Boggess KA, Madianos PN, Preisser JS, Moise KJ Jr, Offenbacher S. Chronic maternal and fetal Porphyromonas gingivalis exposure during pregnancy in rabbits. Am J Obstet Gynecol 2005;192:554-7.

12. Michie CA, Jewell A CD45 and exploring neonatal immunocompromise. J Pediatr Infect Dis 2009;4:193-5.

13. Luciano AA, Yu H, Jackson LW, Wolfe LA, Bernstein HB. Preterm labor and chorioamnionitis are associated with neonatal $\mathrm{T}$ cell activation. PLoS ONE 2011;6:e16698.

14. Kawai T, Akira S. The role of pattern-recognition receptors in innate immunity: update on Toll-like receptors. Nat Immunol 2010;11:373-84.
15. Kumar H, Kawai T, Akira S. Toll-like receptors and innate immunity. Biochem Biophys Res Commun 2009;388:621-5.

16. Fleer A, Krediet TG. Innate immunity: toll-like receptors and some more. A brief history, basic organization and relevance for the human newborn. Neonatology 2007;92:145-57.

17. Funderburg N, Luciano AA, Jiang W, Rodriguez B, Sieg SF, Lederman MM. Toll-like receptor ligands induce human T cell activation and death, a model for HIV pathogenesis. PLoS ONE 2008;3:e1915.

18. Sullivan MH, Steel J, Kennea N, Feldman RG, Edwards AD. The role of intrauterine bacteria in brain injury. Acta Paediatr Suppl 2004;93:4-5.

19. Kristóf K, Kocsis E, Nagy K. Clinical microbiology of early-onset and lateonset neonatal sepsis, particularly among preterm babies. Acta Microbiol Immunol Hung 2009;56:21-51.

20. Sackstein R. The lymphocyte homing receptors: gatekeepers of the multistep paradigm. Curr Opin Hematol 2005;12:444-50.

21. Dudda JC, Martin SF. Tissue targeting of T cells by DCs and microenvironments. Trends Immunol 2004;25:417-21.

22. Sallusto F, Kremmer E, Palermo B, et al. Switch in chemokine receptor expression upon TCR stimulation reveals novel homing potential for recently activated T cells. Eur J Immunol 1999;29:2037-45.

23. Campbell JJ, Haraldsen G, Pan J, et al. The chemokine receptor CCR4 in vascular recognition by cutaneous but not intestinal memory $\mathrm{T}$ cells. Nature 1999;400:776-80.

24. Opiela SJ, Koru-Sengul T, Adkins B. Murine neonatal recent thymic emigrants are phenotypically and functionally distinct from adult recent thymic emigrants. Blood 2009;113:5635-43.

25. Malhotra I, Dent A, Mungai P, et al. Can prenatal malaria exposure produce an immune tolerant phenotype? A prospective birth cohort study in Kenya. PLoS Med 2009;6:e1000116.

26. Steiner K, Myrie L, Malhotra I, et al. Fetal immune activation to malaria antigens enhances susceptibility to in vitro HIV infection in cord blood mononuclear cells. J Infect Dis 2010;202:899-907.

27. Ley K, Kansas GS. Selectins in T-cell recruitment to non-lymphoid tissues and sites of inflammation. Nat Rev Immunol 2004;4:325-35.

28. Grindebacke H, Stenstad H, Quiding-Järbrink $M$, et al. Dynamic development of homing receptor expression and memory cell differentiation of infant $\mathrm{CD} 4+\mathrm{CD} 25$ high regulatory $\mathrm{T}$ cells. J Immunol 2009;183:4360-70.

29. Conroy ME, Shi HN, Walker WA. The long-term health effects of neonatal microbial flora. Curr Opin Allergy Clin Immunol 2009;9:197-201.

30. von Bismarck P, Claass A, Schickor C, Krause MF, Rose-John S. Altered pulmonary interleukin- 6 signaling in preterm infants developing bronchopulmonary dysplasia. Exp Lung Res 2008;34:694-706.

31. Emami CN, Petrosyan M, Giuliani S, et al. Role of the host defense system and intestinal microbial flora in the pathogenesis of necrotizing enterocolitis. Surg Infect (Larchmt) 2009;10:407-17.

32. Petito CK, Adkins B. Choroid plexus selectively accumulates T-lymphocytes in normal controls and after peripheral immune activation. J Neuroimmunol 2005; 162:19-27.

33. Ogunyemi D, Murillo M, Jackson U, Hunter N, Alperson B. The relationship between placental histopathology findings and perinatal outcome in preterm infants. J Matern Fetal Neonatal Med 2003;13:102-9.

34. Sallusto F, Lanzavecchia A, Araki K, Ahmed R. From vaccines to memory and back. Immunity 2010;33:451-63.

35. Rubinstein P, Stevens CE. The New York Blood Center's Placental/Umbilical Cord Blood Program. Experience with a 'new' source of hematopoietic stem cells for transplantation. Ernst Schering Res Found Workshop 2001;33:47-70.

36. Tsuji T, Sakata T, Hamaguchi Y, Wang F, Houwen B. New rapid flow cytometric method for the enumeration of nucleated red blood cells. Cytometry 1999;37:291-301.

37. Yang MH, Lin SJ. Effect of two-round Ficoll-Hypaque density gradient centrifugation on lymphocyte subsets and natural killer activity of umbilical cord blood mononuclear cells. Pediatr Hematol Oncol 2001;18:57-63. 